\title{
Trabalho abstrato, SUbSUnÇÃo E OS DESAFIOS PARA A FORMAÇÃO DO TRABALHADOR NA ATUALIDADE ${ }^{1}$
}

\author{
Rafael Dias Toitio
}

\begin{abstract}
Resumo
0 artigo em questão procura analisar, na atualidade, a formação profissional e técnica, cujo conteúdo e forma têm sofrido mudanças concretas graças à revolução da microeletrônica e, em consequência, à difusão das novas tecnologias de informação (TI), computadores, robótica, softwares etc. Para tanto, procuramos analisar, a partir das reflexões de Marx, a forma de ser do trabalho em nossa sociedade, pois tal forma configura o tipo de formação profissional elaborada pela mesma. Desse modo, apontaremos como velhas tendências apontadas por Marx, e nascidas na Revolução Industrial, se atualizam e se expandem, como a subsunção real do trabalho ao capital e 0 alargamento do trabalho abstrato. Também discutiremos, brevemente, a educação unitária como uma proposta de formação para o trabalhador que abarca, além das questões técnicas, a formação e a organização políticas das classes e grupos subalternos.
\end{abstract}

Palavras-chave: Trabalho abstrato. Formação profissional. Revolução tecnológica. Educação unitária.

\footnotetext{
${ }^{1}$ Agradeço aos professores José Mario Angeli e José Flávio Bertero, da Universidade Estadual de Londrina, cujos debates e trabalhos influenciaram grande parte das ideias presentes nesse artigo.

${ }^{2}$ Mestre em Ciências Sociais pela Universidade Estadual de Londrina e pesquisador do Grupo de Estudos de Política da América Latina (GEPAL).rtoitio@hotmail.com
} 


\section{WORK, SUBSUMPTION AND THE CHALLENGES OF BUILDING PROFESSIONALS NOWADAYS}

\section{Abstract}

This article seeks to analyze, at the present time, the professional and technical training, whose content and form have been through concrete changes due to the microelectronics revolution and, consequently, the spread of new information technologies (IT), computers, robotics, software etc. To this end, we analyze, through Marx's reflexions, what work really is in our society, since it is what defines the professional training developed by this society. Thus, we show how old trends, born in the Industrial Revolution and pointed out by Marx, become updated and expanded as the real subsumption of labor to capital and the expanditure of abstract labor. Finally, we briefly discuss the "unitary school" as proposal for worker training that embraces, besides technical issues, the political education and organization of the subaltern classes and groups.

Keywords: abstract labor. Professional training. Technological revolution. Unitary school.

\footnotetext{
ssim como as demais mercadorias, o valor da força de trabalho é determinado pelo tempo de trabalho necessário para a sua produção e reprodução, sendo expresso por certa quantidade de meios de subsistência (cujo montante é determinado por elementos históricos e morais). 0 vendedor da força de trabalho tem de perpetuar-se por meio do consumo de uma soma de meios de subsistência que o mantém e o sustenta, incluindo os meios de subsistência de seus substitutos no mercado de trabalho (seus filhos) e, ainda, por uma soma de valores para 0 desenvolvimento de sua força de trabalho e aquisição de certa habilidade (MARX, 1978b).
}

A fim de modificar a natureza humana, de modo que alcance habilidade e destreza em determinada espécie de trabalho e se torne força de trabalho desenvolvida e específica, é mister educação e treino que custa uma soma maior ou menor de valores de mercadorias. Esta soma varia de acordo com o nível de qualificação da força de trabalho. Os custos de aprendizagem, ínfimos para a força de trabalho comum, entram, portanto, no total dos valores despendidos para sua produção (MARX, 2006, p. 202). 
É por isso que, no sistema capitalista de produção, há um movimento expansivo de diminuição do tempo de formação profissional exigido para 0 trabalho, a fim de reduzir o valor da força de trabalho.

A desvalorização relativa da força de trabalho, decorrente da eliminação ou da redução dos custos de aprendizagem, redunda, para o capital, em acréscimo imediato de mais-valia, pois tudo o que reduz o tempo de trabalho necessário para reproduzir a força de trabalho aumenta o domínio do trabalho excedente (MARX, 2006, p. 405).

0 encurtamento da formação profissional do trabalhador só pode se dar por meio da simplificação do processo de trabalho que tem se tornado, mais e mais, um processo desqualificado, repetitivo, indiferenciado, alienante e estranho ao trabalhador, que o enfraquece perante o capital. Entretanto, com a introdução de inovações tecnológicas e de novos métodos de gestão do processo produtivo, muitos anunciam, nos dias atuais, o surgimento de um novo trabalho, de caráter criativo e emancipador, o que traria impactos positivos para a formação dos trabalhadores. Mas, qual a real natureza desse "novo" trabalho? Será que a aplicação maciça da ciência e da tecnologia na produção geraria novas qualificações? E quanto aos novos métodos de organização da produção considerados mais "flexíveis"? 0 trabalho repetitivo e estranhado daria espaço a um trabalho criativo? Haveria, assim, um encurtamento entre as etapas de controle, concepção e de execução? Um novo tipo de trabalhador é demandado pelas novas formas produtivas? Tais perguntas constituem o fio condutor de nossa análise que pretende discutir, a partir de uma pesquisa bibliográfica, qual formação profissional está posta atualmente, bem como entender as determinações e tendências que conformam o conteúdo e as formas concretas de manifestação da formação profissional.

Mesmo correndo o risco de cair em uma tautologia, ressaltamos que a educação profissional deve ser analisada a partir da categoria trabalbo, uma vez que a forma de ser do trabalho na sociedade configura o tipo de formação profissional produzida pela mesma. Nesse sentido, para compreendermos que formação profissional está posta hoje, devemos investigar as determinações e relações que conformam o processo de trabalho no sistema capitalista de produção. Para isso, pensamos ser imprescindível o retorno a Marx, em relação às suas formulações sobre o (processo de) trabalho no capitalismo, pelo fato de que, em primeiro lugar, (como veremos) muitas das tendências por ele reveladas sobre o modo de produção capitalista se aprofundam e, em segundo lugar, por ter 
oferecido a fundamentação necessária para conceber uma ontologia a partir da categoria trabalho.

\section{MiCROELETRÔNICA, FORMAÇÃO PROFISSIONAL E SUBSUNÇÃO DO TRABALHO AO CAPITAL}

Sendo ao mesmo tempo processo de trabalho e processo de criar mais-valia, toda produção capitalista se caracteriza por 0 instrumental de trabalho empregar o trabalhador, e não 0 trabalhador empregar 0 instrumental de trabalho. Mas essa inversão só se torna uma realidade técnica e palpável com a maquinaria. Ao se transformar em autômato, o instrumental se confronta com 0 trabalhador durante o processo de trabalho como capital, trabalho morto que domina a força de trabalho viva, a suga e exaure (MARX, 2006, p. 483).

A presente passagem de 0 Capital debate o contexto em que a manufatura capitalista dá lugar à produção assentada na maquinaria e na grande indústria, a partir de uma revolução no próprio modo de produção no processo de trabalho e, por conseguinte, nas relações sociais de produção. Na manufatura, o trabalho estava subsumido formalmente ao capital, no sentido de que o trabalhador, que antes obedecia a um mestre na condição de aprendiz, mostra- se subordinado a um capitalista que, ao deter a propriedade dos meios de produção, explora 0 trabalho alheio na tentativa de expandir o valor de seu capital. Com a Revolução Industrial e o desenvolvimento do sistema de máquinas, o capital pôde superar a produção baseada na manufatura que, do ponto de vista tecnológico, confundia- se com a base técnica artesanal (pois dependia ainda da força e destreza dos trabalhadores). Dá-se início à "subsunção real do trabalho ao capital" (MARX, 1978b, p. 55), ou do modo de produção especificamente capitalista, que se torna forma geral da produção, sendo a mais-valia relativa (ou seja, a redução do trabalho necessário e criação de mais-trabalho) a expressão material dessa fase, que perdura até os dias atuais.

De elemento ativo, o trabalhador passa a intermediar o processo produtivo como um órgão, um apêndice do sistema automático de máquinas, que se torna o "ponto de partida, o lado ativo do processo e da relação" (NAPOLEONI, 1981, p. 88). No capitalismo, a ordem dos fatores de produção é invertida de modo que 0 trabalhador se torna um instrumento, e a máquina perde sua posição de instrumento e se autonomiza, não mais dependendo da força e habilidade do operário. Assim, "não partindo do trabalhador o movimento global da fábrica, 
mas da máquina, pode-se mudar o pessoal a qualquer hora sem interromper o processo de trabalho" (MARX, 2006, p. 481). Nesse sentido, o processo de trabalho deixa de se fundamentar no elemento subjetivo, passando a se organizar, quase que exclusivamente, em torno de um elemento objetivo, do trabalho objetivado, ou seja, de uma coisa.

0 capital, ao se libertar da subjetividade humana, não mais depende da vontade e resistência do trabalhador individual, nem de suas virtualidades, técnicas e habilidades que agora estão materializadas na máquina. É esta que "imprime sobre o trabalho do operário as qualificações que não são mais provenientes da subjetividade do operário e do trabalho, mas são provenientes das exigências, da estrutura e da natureza dessa coisa que é a máquina" (NAPOLEONI, 1981, p. 90). Como um simples órgão de um autômato, o trabalhador se submete à ação da máquina, mais precisamente, de uma "máquina parcial" que se constituiu a partir das ferramentas e técnicas - de parcelização do processo produtivo - do período manufatureiro, o que aprofunda, ainda mais, a divisão do trabalho e as consequências degradantes ao trabalhador ${ }^{3}$. 0 processo de trabalho se torna mero momento do processo de produção de mais-valia, de valorização do capital, em que o trabalho objetivado é um meio para a apropriação e dominação do trabalho vivo, e o próprio trabalho se torna um elemento do capital - esse "autômato" que tem o fim em si mesmo, é senhor de seu próprio processo.

Amáquina em nenhum aspecto aparece como meio de trabalho do trabalhador individual. Sua diferença específica de modo algum é, como no caso do meio de trabalho, a de transmitir ao objeto a atividade do trabalhador; sendo que a atividade se encontra posta de tal maneira que não faz mais que transmitir à matéria prima o trabalho ou ação da máquina, [à] que [o trabalhador] vigia e preserva de danos. Não é como no caso do instrumento, que o trabalhador anima, como a um órgão, com sua própria destreza e atividade, e cujo manejo depende tanto da virtuosidade daquele. Sendo que a máquina, dona da habilidade e da força em lugar do trabalhador, é ela mesma a virtuosa, possui uma alma própria presente nas leis mecânicas que operam nela, e assim como o trabalhador consome alimento, ela consume carbono, óleo etc., (materiais instrumentais) com vistas a seu auto-movimento contínuo. A

\footnotetext{
${ }^{3}$ Marx reconhece que tais degradações não são geradas pela maquinaria em si, mas pela sua utilização capitalista, na que "até as medidas a facilitar o trabalho se tornam meio de tortura, pois a máquina, em vez de libertar o trabalhador do trabalho, despoja o trabalho de todo 0 interesse" (MARX, 2006, p. 483).
} 
atividade do trabalhador, reduzida a uma mera abstração da atividade, está determinada e regulada em todos os aspectos pelo movimento da maquinaria, e não o inverso (MARX, 1971, p. 219).

Assim, se nos modos de produção anteriores o processo produtivo se fundamentava na ação do trabalhador que, com a ajuda do instrumental de trabalho, modificava a matéria-prima, agora o trabalho deixa de ser o elemento central na organização da produção, sendo que a ação sobre a matéria-prima parte da máquina e o trabalho se torna, vale ressaltar, um fator intermediário, um mero apêndice vivo que passa a desenvolver funções simplificadas, mecânicas e repetitivas ${ }^{4}$. Dessa forma, podemos afirmar que há uma tendência do capitalismo de prescindir da formação profissional e técnica dos trabalhadores, na mesma medida em que os processos de trabalho se tornam, com a introdução da maquinaria, cada vez mais simplificados e, nesse sentido, indiferenciados entre si ${ }^{5}$.

Se na manufatura já existe trabalho abstrato (uma vez que já existe troca, e esta é suposto daquele), é, porém, a maquinaria que consolida e efetiva, no âmbito da produção, o caráter abstrato do trabalho. Isso porque pensamos que o trabalho abstrato, formador de valor, deve ser compreendido não apenas como uma generalidade, trabalho humano geral, desgaste físico do trabalhador, mas deve ser analisado como trabalho que se torna cada vez mais uniforme, simples e não diferenciado. Em a Introdução à Crítica da Economia Política, Marx afirma que

A abstração do trabalho em geral não é apenas o resultado intelectual de uma totalidade concreta de trabalhos. A indiferença em relação ao trabalho determinado corresponde a uma forma de sociedade na qual o gênero determinado de trabalho é fortuito, e, portanto, é-lhes indiferente. Neste caso o trabalho se converteu não só como categoria, mas na efetividade em um meio de produzir riqueza em geral, deixando, como determinação, de se confundir com 0 indivíduo em sua particularidade. Este estado de coisas se encontra mais desenvolvido na forma de existência mais moderna da sociedade burguesa - nos Estados Unidos. Aí, pois, a abstração da categoria "trabalho", "trabalho em geral", trabalho sansphrase (sem rodeios), ponto de partida da Economia moderna, torna-se pela primeira vez praticamente verdadeira (MARX, 1978a, p. 119).

\footnotetext{
${ }^{4}$ Cabe dizer, contudo, que como a máquina não forma valor - pois, o valor dela apenas reaparece no valor do produto -, o trabalho vivo (como capital variável), que possui a capacidade de criar valor, jamais desaparecerá do processo.

${ }^{5}$ Ver Bertero e Angeli, 2009.
} 
A redução do trabalho concreto a trabalho abstrato é, nesse sentido, a redução do trabalho complexo, repleto de particularidades a um trabalho simples, homogêneo, não diferenciado. 0 elemento que torna isso possível é a maquinaria, cuja introdução no processo produtivo torna o trabalho "simples, uniforme, geralabstrato que constitui a substância de valor permutável” (MARX, 2008, p. 52)6. Com 0 advento da grande indústria, o valor-de-uso do produto aparece apenas como veículo do valor-de-troca, de forma que o trabalho abstrato é agora predominante em relação ao trabalho concreto e a troca de produtos mediada pelo mercado (pressuposto do trabalho abstrato) se torna geral na mesma medida em que a produção, em sua totalidade, é produção capitalista de mercadorias ${ }^{7}$. Aos poucos, destruiu-se a capacidade produtiva dos trabalhadores no interior do processo de produção, cujas qualificações e virtuosidades não vêm mais da subjetividade dos indivíduos e do trabalho, mas estão materializadas na máquina.

Cabe indagar, entretanto, se esse processo persiste ou não nos dias atuais, ainda mais com o desenvolvimento e a disseminação da base técnica microeletrônica nos sistemas produtivos e na vida social, que levaram muitos intelectuais a afirmarem o surgimento de uma sociedade de novo tipo. Sociedade da informação, do conhecimento, pós-moderna ou pós-industrial, como preferirem, resultado das infinitas possibilidades propiciadas pela transformação tecnológica,

\footnotetext{
6 "Para medir os valores-de-troca [expressões do valor] das mercadorias mediante o tempo de trabalho a elas incorporado, é necessário que os diferentes trabalhos sejam reduzidos a trabalho não diferenciado, uniforme, simples; em síntese: a trabalho que é idêntico pela qualidade e não se distingue senão pela quantidade. Essa redução apresenta a aparência de uma abstração; mas é uma abstração que ocorre todos os dias no processo de produção social. A conversão de todas as mercadorias em tempo de trabalho não supõe uma abstraçãomaior, como tampouco é menos real que a [conversão] de todos os corpos orgânicos em ar. Na realidade, o trabalho que se assim se mede com o tempo não aparece como trabalho de distintos indivíduos; os diferentes indivíduos que trabalham surgem antes com simples órgão de trabalho" (MARX, 2008, p. 54).

${ }^{7}$ Pensamos que, para Marx, a abstração do trabalho ocorre tanto no processo de troca como no processo de produção, e tem como pressupostos a troca, a divisão social do trabalho e a separação do trabalhador de suas condições produtivas. Na sociedade capitalista, o produto dos trabalhadores não é trabalho imediatamente coletivo, social e sim valor; se torna social por meio da troca, onde todos os trabalhos são igualados, parcela de um mesmo trabalho genérico, sendo que, assim, o trabalho individual, concreto, útil, determinado converte-se em coletivo na medida em que se transforma em seu oposto, em trabalho abstrato (NAPOLEONI, 1981, p. 133). Na produção, o trabalho se torna abstrato "materialmente", no sentido de que as qualificações e particularidades do processo de trabalho são cada vez mais negadas, tornando esse processo indiferenciado, homogêneo e, vale dizer, abstrato.
} 
estaria pautada no conhecimento e na informação (e não no trabalho) como os novos pilares e atividade-chave da economia. Isso teria duas influências diretas sobre o trabalho: por um lado, aumentaria o conteúdo de conhecimento do trabalho existente, no sentido que as novas tecnologias adicionariam qualificação aos trabalhadores (principalmente os fabris que passariam a operar máquinas "inteligentes"); e, por outro, haveria a expansão de novos tipos de trabalho no "setor do conhecimento", de modo que os trabalhadores em informação se tornariam predominantes na economia (KUMAR, 2006, p. 62). Assim, um trabalho de caráter criativo, complexo e autônomo estaria supostamente surgindo nessa nova sociedade e, junto com ela, constituir-se-ia o trabalhador do conhecimento.

A constituição da nova base técnica deve ser entendida a partir da formação e concretização de tendências científicas e industriais, historicamente desenvolvidas no seio das forças produtivas. Estas estavam enraizadas na expansão militar imperialista - particularmente dos EUA - e na necessidade de abreviar 0 tempo de trabalho necessário para a produção de mercadorias, que culminaram, nos anos 1940, no desenvolvimento da eletrônica e, depois, da microeletrônica, o que causou um rompimento com a antiga base técnica, a eletromecânica, e desencadeou uma verdadeira revolução tecnológica, uma mudança radical na natureza material da produção capitalista. 0 caráter da automação se modificou qualitativamente com a base técnica microeletrônica, tornou-se agora flexível e propício a se expandir a processos de trabalho antes intocados. Essa revolução na base técnica e produtiva se configurou no pós-guerra e, juntamente com as técnicas do padrão gerencial toyotista, fundamentou a "reestruturação produtiva" nas décadas de 1980 e 1990, gerando modificações substanciais nos processos de trabalho e na formação profissional, que seriam aos poucos reconfigurados pela utilização e difusão de novas tecnologias de informação (TI), computadores, robótica, softwares etc. Todo esse processo provocou profundas transformações não apenas nos processos produtivos e econômicos, mas também nas formas culturais e de sociabilidade, nas dimensões políticas e ideológicas.

Entretanto, tais mudanças não possibilitaram extinguir ou, pelo menos, enfraquecer o processo de subsunção do trabalho ao capital. No que tange à qualificação profissional, se em um primeiro momento em que tais inovações se disseminaram houve, em alguns casos, um acréscimo na qualificação dos trabalhadores e o surgimento de novas ocupações (como programadores, analistas de sistema etc.) demandadas pela nova base técnica. Esta, devido a sua flexibilidade e alto poder de automação, pode materializar perícias e capacidades 
que antes só os seres humanos poderiam fazer, inclusive ligadas ao intelecto, o que tem gerado um efeito "desqualificador", seja nessas novas ocupações ou em ramos que anteriormente possuíam alto grau de qualificação, com formação superior, por exemplo. Vamos a alguns casos.

A introdução das máquinas-ferramentas de controle numérico (MFCN) na automação industrial de pequena escala levou a incorporação, em capital fixo, do saber de um tipo de trabalhador manual que era bastante qualificado. Com os equipamentos anteriores, as máquinas-ferramentas universais (MFU), os oficiais mecânicos (como os torneiros) precisavam desenvolver uma série de habilidades paraproduzirpeçasuniformeseempouco tempo, poistudodependiadeles: ocontrole da máquina, os comandos que estabelecem as posições relativas entre a peça e a ferramenta, a sequência de utilização das ferramentas, a velocidade de avanço e de corte etc. Por isso, ao projetar as peças, o departamento de planejamento levava em conta as opiniões e as destrezas do oficial mecânico que, dessa forma, participava da organização de seu próprio trabalho. Mas com as MFCN, são gravados em mídia todos os movimentos e procedimentos de um operador ao executar uma tarefa: sua atuação sobre a máquina e da máquina sobre o produto em fabricação. Depois, para fabricar mais produtos, é só colocar o programa que gravou os procedimentos na máquina e acionar um botão. Com o avanço da computadorização e dos microchips, os equipamentos se tornaram mais sofisticados e aplicáveis nas mais diferentes indústrias, sobretudo na automobilística e de bens de capital. Ao passar a interagir com uma MFCN, o operador usa muito menos habilidades manuais, coordenação motora e experiência do que antes, o que o torna um mero supervisor, perdendo a condição de participante ativo (TAUILE, 2001). Percebe-se que "não é necessariamente verdade que os equipamentos altamente complexos requerem operadores altamente qualificados, pois a 'qualificação' pode ser incorporada à máquina” (BRIGHT, 1966 apud TAUILE, 2001).

0 mesmo princípio das MFCN é aplicado aos robôs, que provem da adição de um dispositivo de controle baseado na microeletrônica a um manipulador, ou um braço mecânico articulado, sobre uma base que lhe dá solidez e abriga os mecanismos que controlam seus movimentos. No caso de um robô de pintura, por exemplo, para se fazer a sua programação, coloca-se a pistola de pintura na mão de um experiente pintor para que ele pinte o bem produzido, como 0 automóvel. A cada fração de segundo, todos os procedimentos do pintor, inclusive sua localização espacial, são registrados no dispositivo de controle. Então, trata-se de transferir a pistola de pintura para a extremidade do braço mecânico do robô 
e acionar, a cada novo veículo, o programa de procedimentos antes registrado. Os robôs, assim, rompem um conjunto de limites à automação da produção em grande escala. Isso não significa que eles são necessariamente mais rápidos e precisos que os seres humanos quando executam a mesma atividade, porém, seu ritmo de funcionamento é incansável (TAUILE, 2001), o que acaba com as porosidades do processo de trabalho.

No que diz respeito ao trabalho do programador, que surgiu junto com 0 processo de computadorização, Braverman (1987), já na década de 1970, evidenciava como esse trabalho possuía um aspecto de ofício e que aos poucos foi quebrado com a divisão do trabalho e com a automação. De início, o programador era, em geral, um analista de sistemas que combinava as funções de elaborar e escrever o sistema. Com o tempo, essas funções foram fragmentadas de forma que o segundo deveria conceber o sistema e, o primeiro, converter esse sistema em uma série de instruções para o computador. Tal separação se intensificava a medida que ficou claro que grande parte da função de programar era rotina e podia ser delegada a funcionários mais baratos. Além disso, Tauile (2001) argumenta que a rotinização da programação e as inovações em equipamentos de automação flexível e o desenvolvimento de softwares reduzem drasticamente a necessidade de programação, cujo trabalho tende a ser substancialmente simplificado e sistematizado. Assim, ao programar, isto é, transferir progressivamente seus conhecimentos à memória dos equipamentos, o programador programa sua própria programação (TAUILE, 2001).0 trabalho em escritório, que já havia passado por um processo fragmentação, padronização e desqualificação, tornouse um alvo fácil para automação de seus procedimentos e funções, que agora eram rigidamente controlados pelo computador e o sistema informacional. De acordo com Kumar (2006, p. 60):

Os funcionários de escritório tornaram-se, como eles mesmos costumam dizer, 'escravos do computador', meros alimentadores de máquinas, sem virtualmente a mínima compreensão do objetivo geral do trabalho que realizam ou de controle do ritmo em que operam. Pouco conhecimento ou treinamento é necessário para executar as tarefas rotineiras envolvidas na preparação de dados para o computador ou para gravá-los em disquetes ou fitas.

Um olhar mais atento nos leva a perceber a nítida degradação do trabalho de escritório e de serviço e, também, em processos que envolvem alta tecnologia. Um fenômeno de origem recente, que de certa forma abrange ambos os casos, 
é o trabalho do teleoperador, fundamentalmente regulado pela pressão do fluxo informacional e subordinado a um rígido script (roteiro), cujo objetivo central consiste em aumentar a eficácia comercial associada á redução do tempo de conexão, tendo em vista a multiplicação das chamadas por hora trabalhada. A autonomia do teleoperador, cuja comunicação é rotinizada, é significativamente reduzida enquanto os supervisores (uma média de um para quinze ou vinte funcionários) escutam as comunicações para assegurar a obediência ao script. Com a automação do trabalho do teleoperador, os ganhos de produtividade são alcançados à custa de um acentuado aumento de fadiga física, da postura automatizada, dos contratos de trabalho em tempo parcial, do desinteresse pela função, da vertigem oriunda da multiplicidade das chamadas, das Lesões por Esforço Repetitivo (LERS), etc. (BRAGA, 2007).

Além disso, o desenvolvimento dos softwares possibilitou mecanizar e, ao mesmo tempo, desqualificar o trabalho intelectual e as profissões de nível superior. Engenheiros têm, aos poucos, seu conhecimento matemático e sobre as condições do material trabalhado sendo incorporado em programas de cálculo e de dimensionamento. Arquitetos e desenhistas industriais tiveram seu trabalho simplificado pelos programas Computer Aided Design (CAD). Diversos outros profissionais de nível superior - na medicina e na educação, por exemplo - vêem seu trabalho ser monitorado e sua perícia desafiada por sistemas de inteligência artificial (KUMAR, 2006, p. 61).

Nesse sentido, não há fundamentação nos argumentos que defendem e propagam o surgimento de uma nova sociedade pautada na (re)qualificação profissional e no surgimento do trabalhador do conhecimento. Se realmente existem determinados ramos profissionais que apresentam um gratificante trabalho qualificado, como os pequenos núcleos de cientistas responsáveis pela elaboração e concepção de equipamentos e técnicas baseados na microeletrônica, isso não é nada mais do que uma expressão contemporânea da dicotomização, cada vez mais radical, entre os que concebem e controlam e os que executam 0 processo de trabalho. Mesmo em profissões que antes eram tidas como altamente qualificadas, hoje tem seu trabalho rotinizado e sua formação diminuída e barateada. Gorz (1982) nos aponta como a automatização e a informática desqualificam o trabalho na medida em que a evolução da técnica tende a:

[...] substituir a intervenção inteligente do trabalhador por regulamentos e controles automáticos, os quais [...] fazem dos 'operadores' aquelas pessoas 
fatigadas que vêem a máquina impor-lhes inexoravelmente um número preciso de gestos que exigem a maior atenção e a mais completa vacuidade de espírito (GORZ, 1982, p. 153).

É evidente que nos dias atuais estão surgindo nas novas gerações outras habilidades demandadas pela base técnica microeletrônica. Crianças (sobretudo das camadas "médias" e "altas" da população) ainda não alfabetizadas possuem, muitas vezes, maior facilidade para lidar com o computador do que seus pais e avós, já que crescem em ambientes cujas relações são altamente mediadas pelas tecnologias ${ }^{8}$. 0 trabalhador, nos processos produtivos automatizados, precisa desenvolver uma maior capacidade de abstração para poder enxergar a integração do processo produtivo pelos sistemas informacionais. Entretanto, o surgimento de novas habilidades não significa necessariamente uma qualificação do trabalho. As recentes transformações tecnológicas levam justamente para uma direção contrária: o de simplificação do processo de trabalho e homogeneização da formação dos trabalhadores.

A caixa de supermercado e a recepcionista de uma biblioteca, ou ainda 0 controlador de um almoxarife, utilizam todos uma caneta ótica para leitura do código de barras. [...]. 0 piloto de avião e 0 operador de máquinas de ferramentas de controle numérico também têm que agir (e reagir) sobre teclados e alavancas, de modo similar, em função dos símbolos e figuras que aparecerão nas telas diante de si. Em outras palavras, com a convergência tecnológica abrangendo segmentos da atividade econômica os mais diversos, a diferenciação profissional no interior do mercado de trabalho está se tornando significativamente mais tênue e as fronteiras entre as qualificações básicas necessárias ao exercício de muitas (e antes diferentes) profissões, sendo diluídas como nunca (TAUILE; FARIA, 1999, p. 171-172).

Estamos, mais uma vez, diante do aprofundamento do movimento de crescente aplicação da ciência no processo de produção, que diminui o trabalho vivo e desqualifica o trabalhador, uma vez que suas virtudes e potencialidades são materializadas na máquina (capital fixo), de forma a tornar indiferente as

\footnotetext{
${ }^{8}$ Sobretudo com base na experiência estadunidense e europeia, Hobsbawm (1995, p. 320) analisa como a mudança tecnológica deu aos jovens, principalmente para as primeiras gerações que tiveram contato com os computadores e seus programas, uma vantagem sobre os grupos etários mais velhos: "mesmo quando essas máquinas e programas eram, espera-se, à prova de erro, a geração que não crescera com eles tinha uma aguda consciência de sua inferioridade em relação às gerações que o haviam feito. 0 que os filhos podiam aprender com os pais tornou-se menos óbvio do que o que os pais não sabiam e os filhos sim".
} 
qualificações requeridas pelos diversos ramos de atividade. 0 capital se fortalece na medida em que independe cada vez mais do conhecimento e das habilidades do trabalhador, que tem seu poder diminuído, já que sua qualificação é uma importante arma no confronto com o capitalista. A desqualificação, ao contrário, torna o trabalhador mais barato, supérfluo e facilmente substituível. A revolução técnico-científica propiciada pela microeletrônica reduz o montante de trabalho vivo no processo produtivo, o que, por um lado, - e graças também às baixas taxas de crescimento do capitalismo - tem jogado um contingente crescente de trabalhadores no exército industrial de reserva e, por outro, aumentou a composição orgânica do capital, o que pode levar a novas crises de superacumulação de capital.

0 desenvolvimento de novas tecnologias que subvertem as condições de produção e gera o movimento de simplificação e homogeneização do processo de trabalho, possui como pano de fundo a universalização do trabalho social e, mais precisamente, o alargamento do trabalho abstrato. Na condição de mero meio de valorização do capital, o trabalho é trabalho abstrato, sua forma de existência cada vez mais predominante na sociedade capitalista que se amplia em ramos antes não produtivos. Por isso, não concordamos com a tese de Habermas (1987, p. 105) de que "a utopia de uma sociedade do trabalho perdeu sua força persuasiva [...]. Acima de tudo, a utopia perdeu seu ponto de referência com a realidade: a força estruturadora e socializadora do trabalho abstrato". Pelo contrário, o trabalho abstrato continua a possuir sua "força estruturadora e socializadora" na medida em que, no sistema capitalista, ele é universal. E mais, é universal concreto, isto é, se realiza e se expressa no trabalho concreto, individual de cada trabalhador. 0 trabalho abstrato, consolidado pela grande indústria, é universal não apenas por se tratar (conforme apontamos) de uma generalidade (por ser desgaste físico do trabalhador, por exemplo), mas porque, no processo de geração de valor, o trabalho se torna cada vez mais, e cotidianamente, uniforme, simples e não diferenciado (FAUSTO, 1983). Com o aperfeiçoamento da máquina a partir do desenvolvimento da microeletrônica, o trabalho se tornou ainda mais simples, está perdendo as suas especificidades e, dessa forma, se universaliza. Juntamente com a industrialização generalizada, a universalidade do trabalho abstrato revela o avanço das forças produtivas, o que dissolve relações arcaicas e indica a possibilidade de abolição da divisão do trabalho, seguramente não sob o capitalismo, mas em outra forma de sociedade (BERTER0, 2001). 
No entanto, as transformações técnicas e econômicas que o sistema capitalista vem sofrendo não destruíram a preponderância do trabalho abstrato nem o domínio do capital sobre o trabalho, ao contrário, fortaleceram tais posições, a partir da aplicação tecnológica da ciência no processo produtivo. Velhas tendências apontadas por Marx, e nascidas na Revolução Industrial, se atualizam e se expandem sobre atividades que não eram acessíveis à antiga base técnica. Automação, divisão do trabalho, aumento da composição orgânica do capital, desemprego, industrialização generalizada, formação profissional homogênea etc., são algumas expressões do desenvolvimento e "renovação" das forças produtivas nas últimas décadas do século XX. A "revolução" microeletrônica, longe de propiciar o surgimento do "trabalhador do conhecimento", faz parte do processo mais amplo de subsunção real do trabalho ao capital.

\section{QUAL FORMAÇÃo É NECESSÁRIA AO TRABALHADOR HOJE?}

Diante do acima exposto, faz sentido debater sobre as questões relativas à educação profissional? Em um primeiro momento, sim, haja vista que o fato de a base técnica própria do capitalismo prescindir da formação para o trabalho não ser mais do que uma tendência, ou seja, não se efetivou de modo concreto e definitivo. Embora o tempo de formação profissional tenha sofrido uma drástica compressão, o surgimento de novas técnicas, habilidades e conhecimentos específicos ligados às inovações tecnológicas e organizacionais precisam ser repassados às novas gerações. Porém, se pensarmos a partir da perspectiva da construção da consciência dos trabalhadores, a educação não pode se restringir aos aspectos técnico-científicos, os quais devem estar também entrelaçados aos aspectos políticos, culturais e sociais. Essa é a proposta de educação unitária de Gramsci (2006) que une formação técnica e científica com a formação geral e humanista, de modo a articular, organicamente, teoria e prática, concepção e ação, conhecimento geral e específico, ou seja, tenta destruir processualmente a divisão entre trabalho intelectual e trabalho manual. A escola unitária deveria substituir a escola fundamental e média, sendo sua abrangência universal, isto é, aberto para todas as classes sociais. Gramsci trata dessa questão no Caderno 12, no qual debate sobre a criação e formação, a médio e longo prazo, dos intelectuais, concebidos por ele como organizadores políticos, dirigentes. Mostra que a base do "novo" intelectual deve ser 0 trabalhador e é ele que a educação unitária deve formar. 
0 modo de ser do novo intelectual não pode mais consistir na eloquiência, motor exterior e momentâneo dos afetos e das paixões, mas numa inserção ativa na vida prática, como construtor, organizador, "persuasor permanentemente", já que não apenas orador puro - mas superior ao espírito matemático abstrato; da técnica-trabalho, chega à técnica-ciência e à concep̧̧ão humanista histórica, sem a qual permanece "especialista" e não se torna "dirigente" (especialista + político) (GRAMSCI, 2006, p. 53).

0 trabalho é o princípio educativo capaz de unificar técnica e política, ou seja, de atribuir, por um lado, sentido histórico e político às formas e procedimentos do processo de trabalho; por outro, pode dar concreticidade aos temas e conteúdos a serem aprendidos, evitando, assim, as abstrações desarticuladas e enciclopédicas do ensino oficial. Na perspectiva da epistemologia, esse princípio oferece unidade aos diversos eixos e áreas do conhecimento, a partir de uma noção ampla de trabalho, como atividade vital da formação do ser social, fundante das diversas dimensões humanas: estéticas, políticas, culturais, valorativas etc. Com o projeto de educação unitária, Gramsci (2006) segue os caminhos da proposta defendida por Lênin da escola única do trabalho, na URSS, e das medidas discutidas por Marx sobre a educação da classe trabalhadora, já presente no Manifesto, onde preconiza a "combinação da educação com a produção material" (MARX; ENGELS, 2006, p. 107). Nas "Instruções para os Delegados do Conselho Geral Provisório", redigidas para o Conselho Central Provisório do I Congresso da Associação Internacional dos Trabalhadores, Marx defende um projeto de educação composto pela educação intelectual, educação física e educação tecnológica, destinando-se esta última a oferecer os princípios gerais e científicos de cada tipo de produção e ao mesmo tempo iniciar os rapazes e jovens no uso prático dos instrumentos elementares de todas as profissões (MARX, 1982).

Entretanto, faz-se necessário objetar como é possível eleger o trabalho como princípio pedagógico no processo de educação das classes subalternas se, na sociedade atual, ele toma a forma de trabalho assalariado e é causa da alienação e estranhamento nos trabalhadores?

Pensamos que, num primeiro momento, o trabalho que deve ser o princípio educativo é aquele concebido como fonte ineliminável da formação humana, como força estruturadora da sociedade, base da materialidade social. 0 trabalho pensado historicamente abstrato, para justamente mostrar sua historicidade, ou seja, evidenciar que é atividade vital para qualquer formação social, mas que, no capitalismo, toma a forma de trabalho assalariado. Por isso, que a educação 
unitária deve privilegiar a historicidade e a perspectiva da totalidade para demonstrar a forma de ser do trabalho no capitalismo. E, ainda, evidenciar que tal forma se desenvolve contraditoriamente, uma vez que o capital, ao tender sempre à forma geral da riqueza, impele o trabalho para além dos limites das necessidades naturais, criando, assim, os elementos materiais para o desenvolvimento de uma rica individualidade, omnilateral em sua produção e consumo. 0 trabalho não aparece mais como trabalho e sim como pleno desenvolvimento da própria atividade, na qual desaparece a necessidade natural em sua forma imediata que, em seu lugar, colocou-se uma necessidade historicamente dada (MANACORDA, 1996, p. 51). Nesse sentido, a educação articulada à produção material deve, antes de tudo, escancarar a natureza antagônica do trabalho, que consiste no desenvolvimento do trabalho como um momento vil e alienante e, ao mesmo tempo, como atividade vital humana: o trabalho é "por uma parte, a miséria absoluta enquanto objeto e, por outra parte, a possibilidade absoluta de riqueza, enquanto sujeito e atividade" (MARX apud MANACORDA, 1996, p. 52).

Segundo Marx (2006), a indústria moderna, com suas próprias catástrofes,

Torna questão de vida e morte substituir a monstruosidade de uma população operária miserável, disponível, mantida em reserva para as necessidades flutuantes da exploração capitalista, pela disponibilidade absoluta do ser humano para as necessidades variáveis do trabalho; substituir o indivíduo parcial, mero fragmento humano que repete sempre uma operação parcial, pelo indivíduo integralmente desenvolvido, para 0 qual as diferentes funções sociais não passariam de formas diferentes e sucessivas de sua atividade. As escolas politécnicas e agronômicas são fatores desse processo de transformação, que se desenvolveram espontaneamente na base da indústria moderna; constituem também fatores dessa metamorfose as escolas de ensino profissional, onde os filhos dos operários recebem algum ensino tecnológico e são iniciados no manejo prático dos diferentes instrumentos de produção. A legislação fabril arrancou ao capital a primeira e insuficiente concessão de conjugar a instrução primária com o trabalho na fábrica. Mas não há dúvida de que a conquista inevitável do poder político pela classe trabalhadora trará a adoção do ensino tecnológico, teórico e prático, nas escolas dos trabalhadores. Também não há dúvida de que a forma capitalista de produção e as correspondentes condições econômicas dos trabalhadores se opõem diametralmente a esses fermentos de transformação e ao seu objetivo, a eliminação da velha divisão do trabalho. Mas o desenvolvimento das 
contradições de uma forma histórica de produção é o único caminho de sua dissolução e do estabelecimento de uma nova forma (MARX, 2006, p. 553).

Podemos observar que, para Marx, a educação baseada no trabalho pode ser um elemento de transformação no processo de ruptura da ordem capitalista, de forma que o novo nasce no velho, a partir das próprias contradições deste. De modo dual, a indústria moderna desenvolve as condições objetivas para a construção da emancipação humana: na fábrica mecanizada, o trabalho braçal perde todo caráter de especialização, o que, no entanto, justamente quando cessa todo desenvolvimento especial, faz-se sentir também a tendência ao desenvolvimento omnilateral do indivíduo. A apropriação privada dos meios de trabalho significou, também, a apropriação privada da ciência e sua separação do trabalho negou o preexistente vínculo entre ciência e ação, próprio da limitada produção artesanal, mas criou por sua vez as condições para a sua própria superação (MANACORDA, 1996). 0 trabalho simplificado, reduzido pelo capital a um mínimo, torna "útil o trabalho emancipado e constitui a condição de sua emancipação" (MARX apud MANACORDA, 1996, p. 60). É por isso que Gramsci afirma que, "no mundo moderno, a educação técnica, estreitamente ligada ao trabalho industrial, mesmo ao mais primitivo e desqualificado, deve constituir a base do novo tipo de intelectual" (GRAMSCI, 2006, p. 53). Em outras palavras, ele está preocupado com a formação do sujeito que será responsável pela produção de riquezas da sociedade emancipada e, ao mesmo tempo, conduzirá o processo político de destruição das classes e do Estado: a sociedade comunista, fundamentada no trabalho associado, longe de retroceder às formas de trabalho complexo próprias do artesanato, parte do trabalho simples para poder construir os caminhos de emancipação e desenvolvimento humano para além da esfera da produção, do "reino da necessidade".

0 desenvolvimento das potencialidades humanas tem como pressuposto 0 desenvolvimento das condições materiais de existência erigidas no capitalismo 9 . A criação da base técnica do capital pela ciência gerou as condições prévias para que o dispêndio de esforços humanos se reduza a um mínimo no processo de produção e para que o lugar dos trabalhadores segmentados de hoje seja ocupado por indivíduos desenvolvidos de forma multifacética (ROSDOLSKY, 2001, p. 353).

\footnotetext{
${ }^{9}$ Nos Grundrisse, Marx nos chama atenção para o seguinte fato: "se a sociedade, tal como é, não contivesse, ocultas, as condições materiais de produção e de circulação necessárias a uma sociedade sem classes, todas as tentativas de criá-la seriam quixotescas" (MARX, 1953 apud ROSDOLSKY, 2001, p. 353).
} 
Contudo, o desenvolvimento omnilateral dos indivíduos, em uma sociedade baseada no tempo livre, extrapola a esfera material na medida em que não é por meio do trabalho que os indivíduos poderão desenvolver suas múltiplas dimensões e sim por meio das artes, filosofia, esporte, política, cultura etc. Nesse processo, torna-se inevitável a recuperação de uma identidade entre ciência e trabalho, isto é, a reapropriação da ciência por parte de todos os indivíduos no processo coletivo da produção moderna. A educação passa a ser configurada a partir da coincidência entre ciência e trabalho; uma ciência não meramente especulativa, mas operativa que reflita a capacidade do homem dominar a natureza; e um trabalho articulado à tecnologia e às modernas formas de produção (MANACORDA, 1996). Uma ciência que seja reincorporada pela força produtiva do trabalho, de forma que os trabalhadores deixem de ser mero apêndice e passam a ser dirigentes do processo global de produção. E isso é tão mais possível na medida em que a microeletrônica se desenvolve e permite a destruição da ruptura entre o trabalho manual e o trabalho intelectual, uma vez que este se torna mais e mais simplificado e homogêneo.

A formação para o trabalho, hoje, deve estar em consonância com a atual base técnica, a microeletrônica, pois o contrário seria cair em um anacronismo desnecessário. Entretanto, ela deve ir para além dessa perspectiva, pois deve abarcar também a formação política, capaz de oferecer o conhecimento das mediações e determinações presentes na realidade efetiva e que constituem os nexos que estruturam a sociedade em classes. A proposta de educação unitária surge no sentido de desenvolver a autonomia e uma nova cultura dos trabalhadores, antagônica àquela da burguesia, em um movimento de auto-educação da classe. 0 sujeito que deve se auto-educar não se restringe mais ao operário fabril de que se referia Marx, Gramsci e tantos outros. 0 alargamento das relações capitalistas de produção, a expansão do trabalho abstrato, a simplificação do processo de trabalho em ramos antes intocados - diminuindo o poder do trabalhador perante o capital -, o aumento do exército industrial de reserva etc. complexificaram o mundo do trabalho e engendraram sérias implicações políticas. 0 proletário, responsável pela produção de mais-valia, ainda é central para a construção de uma sociabilidade assentada no trabalho associado por encarnar o antagonista direto do capital, isto é, por estar no cerne da contradição. Porém, a base do "novo intelectual" deve abarcar também as frações das classes trabalhadoras que, apesar de não produzirem mais-valia, têm suas condições de trabalho e vida determinadas pelo movimento de valorização do capital, como os desempregados, semi-proletários, assalariados da esfera da circulação, assalariados do Estado (como os professores) etc. 
A luta dos trabalhadores para garantir e aprofundar a própria cultura, para se apropriar do conhecimento, traria consigo o esforço e o empenho para assegurar a sua autonomia em relação aos intelectuais da classe dominante e ao seu poder despótico. Assim, há necessidade de criação de um novo processo educativo: a auto-educação dos trabalhadores, pautada no trabalho como fundamento da sociabilidade emancipada do homem (DEL ROIO, 2006). 0 partido, no sentido amplo, tem um papel decisivo nesse processo, pois é o sujeito coletivo que deve assegurar a autonomia da nova cultura, voltada para o trabalho associado, rompendo com a cultura, sociabilidade e institucionalidade liberais. Deve, além disso, se propor a ser educado pelas circunstâncias e pelo movimento das classes trabalhadoras em um processo político orgânico. Aqui, a educação deixaria de ser mera reprodutora das relações capitalistas e passaria a atuar ativamente como instrumento de organização, conscientização e formação política das classes e grupos subalternos.

\section{REFERÊNCIAS}

BERTER0, Jose Flavio. Os novos proletários do mundo na virada do século. Revista Mediações, Londrina, v. 6, n. 2, p. 149-177, 2001.

BERTERO, Jose Flavio; ANGELI, José Mario. Educação politécnica ou educação política nas condições atuais do trabalho. Revista Espaço Acadêmico, ano 9, n. 102, nov. 2009. Disponível em: <http://periodicos.uem.br/ojs/index.php/ EspacoAcademico/article/viewFile/8591/4811 >. Acesso em: 2 dez. 2009.

BRAGA, Ruy. Avingança de Braverman ou a "outraface" do trabalho informacional. Outubro, São Paulo, v. 15, p. 121-149, 2007.

BRAVERMAN, Harry. Trabalho e capital monopolista. A degradação do trabalho no século XX. Rio de Janeiro: Zahar, 1987.

DEL R0I0, Marcos. Gramsci e a educação do educador. Cad. Cedes, Campinas, v. 26, n. 70, p. 311-328, set./dez. 2006. Disponível em: <http://www.scielo.br/pdf/ ccedes/v26n70/ a03v2670.pdf>. Acesso em: 4 fev. 2010.

FAUSTO, Ruy. Abstração real e contradição: sobre o trabalho abstrato e 0 valor. In: . Marx: lógica e política. São Paulo: Brasiliense, 1983. p. 89-138.

GORZ, André. Adeus ao proletariado. Rio de Janeiro: Forense. 1982.

GRAMSCI, Antonio. Cadernos do cárcere. 2. ed. Rio de Janeiro: Civilização Brasileira, 2006. v. 2. 
HABERMAS, Jürgen. A nova intransparência. Novos Estudos, São Paulo, n. 18, p. 103-114, 1987.

HOBSBAWM, Eric. Era dos extremos: o breve século XX - 1914-1991. 2. ed. Tradução de Marcos Santarrita. São Paulo: Cia. das Letras, 1995.

KUMAR, Krishan. Da sociedade pós-industrial à sociedade pós-moderna. Tradução de Ruy Jungmann. Rio de Janeiro: Jorge Zahar, 2006.

MANACORDA, Mario Alighiero. Marx e a pedagogia moderna. Tradução de Newton Ramos de Oliveira. 2. ed. São Paulo: Cortez, 1996.

MARX, Karl. Contribuição à crítica da economia política. Tradução de Florestan Fernandes. 2. ed. São Paulo: Expressão Popular, 2008.

Elementos fundamentales para la critica de la economia política (Grundrisse) 1857-1858. México: SigloVeintiuno, 1971.

. Instruções para os delegados do Conselho Geral Provisório. As diferentes questões. In: MARX, Karl.; ENGELS, Friedrich. Obras escolhidas. Tradução de José Barata-Moura. Lisboa: Avante, 1982. Disponível em: <http://www.marxists.org/ portugues/marx/1866/08/instrucoes.htm\#n41>. Acesso em: 4 ago. 2010.

. Manuscritos econômicos-filosóficos e outros textos escolbidos. 2. ed. São Paulo: Abril Cultural, 1978a. (Os pensadores).

. 0 Capital: livro I capítulo VI (inédito). São Paulo: Ciências Humanas, 1978b. . O Capital: crítica da economia política. Livro I. Tradução de Reginaldo Sant’Anna. 24. ed. Rio de Janeiro: Civilização Brasileira, 2006.

MARX, Karl; ENGELS, Friedrich. Manifesto do partido comunista. 10. ed. São Paulo: Global, 2006.

NAPOLEONI, Claudio. Lições sobre o capítulo VI (inédito) de Marx. Tradução de Carlos Nelson Coutinho. São Paulo: Ciências Humanas, 1981.

ROSDOLSKY, Roman. Gênese e estrutura do o capital de Karl Marx. Tradução de César Benjamim. Rio de Janeiro: EDUERJ: Contraponto, 2001.

TAUILE, Jose Ricardo. Para (re)construir o Brasil contemporâneo: trabalho, tecnologia e acumulação. Rio de Janeiro: contraponto, 2001.

TAUILE, Jose Ricardo; FARIA, Luiz Augusto. E. As transformações do capitalismo contemporâneo e sua natureza na análise de Marx. Revista de Economia Política, São Paulo, v. 19, n. 1, p. 158-181, jan./mar. 1999. 